\title{
Routinisation of Audience Participation: BBC News Online, Citizenship and Democratic Debate
}

\author{
EINAR THORSEN, Bournemouth University, ethorsen@bournemouth.ac.uk
}

Leading up to the 2010 UK general election, Director General of the BBC, Mark Thompson, stressed the importance of the Corporation's ability 'to provide a strong and independent space where the big debates can take place, free from political or commercial influence'. 'In this public space,' he continued, 'everyone can have access to the lifeblood of healthy democratic debate - impartial news and information'. Affirming the importance of BBC Online, Thompson described it as 'being a cornerstone of what the BBC should be about' (Thompson, 2010).

As with previous elections, one of the key strategic priorities for the BBC's Election 2010 website was to help inform the citizenry about the campaign and empower voters to make an informed choice. In the most traditional sense, this was achieved through the BBC's journalism and a series of rich background features - e.g. guidance on voting procedures, MPs and parliamentary politics, and comparisons of party manifestos. The BBC election websites have also featured experimentation with various forms of audience engagement, exemplified by different interactive features on the BBC micro websites for the 1997, 2001, 2005 and 2010 UK general elections. This has traditionally been anchored in the Corporation's public service commitment to facilitating 'civic engagement' and providing 'democratic value' to British citizens (see also Thorsen et al., 2009, Thorsen, 2010, 2011, Allan and Thorsen, 2010).

The BBC's news website was incredibly popular during the 2010 election according to visitor statistics. On results day, May 7, BBC News Online had 11.4 million individual users, breaking the previous record set on November 5, 2008, for the election of Barack Obama as US President (Herrmann, 2010). Comparing this to 2005, the number of unique visitors to the BBC's election site on results day, May 6, was 3 million taking the overall BBC News Online total to 4.3 million (Ward, 2006:17). This demonstrates a near three-fold increase in individual users from one election to the next and indicates that whilst the internet might not be perceived as having had a significant impact on the election outcomes, the BBC has certainly had a considerable impact on citizens' online activities.

Based on a larger study into BBC's election websites involving interviews, observations and textual analysis, this chapter will examine how audience participation had by 2010 become a routinised part of the Corporation's newsroom. It will begin by providing an historical overview of how public access programming has developed within the BBC and its influence on how the Corporation has sought to facilitate participatory spaces online. Following a discussion of online participatory spaces on the BBC's election websites, it will offer a critique of how these are operationalized internally. It will argue that despite converged newsroom practices, the scale of the BBC's operations means facilitation of civic engagement is fragmented between competing stakeholders within the Corporation each with their own routinised practices and perception of its value. This tension has a dramatic effect not only on the dialectic relationship between BBC journalists and its audiences, but also on the type of 'public space' the Corporation is able to foster and by extension the empowerment of citizens to engage in 'healthy democratic debate'. 


\section{THE BBC AS FORUM FOR PUBLIC DEBATE}

The BBC has since its early days had an intricate relationship with British citizens. John Reith as the first Managing Director of the BBC was determined that it should serve the whole nation, eventually guided by the overarching mission to 'inform, educate and entertain'. Assuming this responsibility in the name of public service, the BBC represented not just a new communications technology, but in the words of William Robson a 'sociological invention of immense significance' (cited in Curran and Seaton, 2003:111) that ensured the BBC developed into one of the key institutions shaping citizenship in British society.

Reith firmly believed that the people involved had done their 'best to found a tradition of public service rather than public exploitation'. In his view, '[t]he broadcasting system of a nation is a mirror of that nation's conscience' (cited in MacDonnell, 1991:15). Despite such laudable ideals, Reith's perception of what constituted Britain's 'conscience' was grounded in a rather elitist philosophy, and the BBC was frequently accused of being too paternalistic and top-down in its programming (see Born, 2002). The perceived elitism was also evident in the interpretation of how the $\mathrm{BBC}$ would 'provide a forum for public debate' - one of four major criteria governing $\mathrm{BBC}$ programme making in the early years. C. A. Lewis, the BBC's organiser of programmes in 1924 proclaimed that the $\mathrm{BBC}$ :

must establish itself as an independent public body, willing to receive any point of view in debate against its adversary. Its unique position gives the public an opportunity they have never had before of hearing both sides of a question expounded by experts. This is of great general utility, for it enables 'the man in the street' to take an active interest in his country's affairs.

(C. A. Lewis cited in MacDonnell, 1991:13)

It is clear that the notion of allowing most citizens a direct voice, was out of question. Instead 'the man in the street' would be enlightened, or even empowered, by the diversity and plurality of experts' points of view provided by the BBC. Nevertheless, one of the founding principles of the Corporation was that it would facilitate public debate and in so doing enhance democratic society through informed citizens.

The immediate post-war period saw the $\mathrm{BBC}$ pioneer political discussion programmes on radio where ordinary members of the public were able to participate for the first time. Any Questions?, which is still being broadcast on Radio 4, first started regular national broadcasts in 1950 . The format of the show typically features a panel comprising of four politicians or other public figures who answer questions put to them by an audience made up from the locality being visited. Experimentation with audience interaction on radio picked up pace in the 1960s with the introduction of the radio phone-in format. Interestingly, the quality of debate was often perceived as being poor since 'the British public were largely unaccustomed to requests for their views' (Hibberd, 2003:49). People quickly adapted, however, with the advent of commercial radio in 1973 spawning a plethora of local and eventually national phonein programmes. Public access programming was taken to another level with the introduction of BBC Radio Five Live in 1994 and the commercial station Talk Radio 
(later Talk Sport) in 1995 - stations wholly dedicated to news and sports with a central focus on citizen's voices and phone-in programmes (Hibberd, 2003:50).

In terms of television, the perhaps most iconic of the BBC's political audience participation programmes, Question Time, was launched in 1979. Originally chaired by Robin Day the weekly programme was based on a similar format to radio's Any Questions? described above. Questions were taken from audience members prior to broadcast and the chair selected some that are put to a panel of guests (one each from the three major parties and one other public figure, but extended in 1999 to encompass two non-partisan members). Although it was intended as a short series, the format's popularity among the public has ensured that it is still being broadcast today - Robin Day was replaced by Peter Sissons in June 1989 who in turn gave up the reins in 1993 with David Dimbleby taking over since 1994. This rise of public access programming has also been evident in the commercial sector. In the case of television, ITV (e.g. Sunday lunchtime slot), Channel 4 (e.g. On Trial... series), Channel 5 (e.g. The Wright Stuff) and Sky (e.g. Your view) all scheduled programmes where the voice of ordinary people were in one way or another centre stage.

Clearly public access programming, focussing as it often does on politics and current affairs, resembles at least superficially something of a public sphere. However, the question-answer-debate format as described above has been criticised by the likes of Bourdieu (1998) for being an artificial construct, or in McNair's (2000) words 'an illusory form of access which symbolically reasserts the status division and power disparities which exist between leaders and led, elite and mass' (McNair, 2000:113, see also Livingstone and Lunt, 1994). Nevertheless, despite its limitations, this carefully mediated form of participation does serve a purpose insofar as it enables a limited degree of public interrogation of politicians and symbolically positions the public as part of a public sphere. 'They may not be perfect expressions of citizenpolitician dialogue', McNair contends, 'but they are valuable as a means of direct public access-by-proxy to politicians who are otherwise largely free of any obligation to confront the public' (McNair, 2000:113)'.

Indeed, while Ross (2004) found that callers to BBC's Election Call during the 2001 UK election did much less talking than the politicians, there was enough evidence to support the notion that the programme facilitated 'some kind of dialogue, even if this sometimes meant rude interruptions and frustration' (Ross, 2004:799). Deliberating with politicians is particularly problematic during election time, since the political parties essentially 'lock' their policies prior to the campaign by publishing a policy manifesto. Thus the debate will be artificially focussed on those priorities - which may or may not be aligned with the priorities of members of the public - and the majority of party political actors will dogmatically follow the principles set out in these documents, regardless of rational and persuasive argument. After all, within a representative democracy such as what exists in the UK, voters need to be able to have a clear sense of what each party claim to represent in order to make an informed choice. Discussions at election time are thus limited to an exchange about truth claims or promises made within election manifestos with persuasion only working in one direction, as opposed to a truly deliberative dialogue between politicians and the electorate. This, according to Ross, did not diminish the functional value of Election Call in the eyes of the citizens participating: 
While callers consciously acknowledged that politicians were unlikely to change their minds and policies as a consequence of their own critical intervention, they were much more optimistic about the programme's awareness-raising potential among the listeners, which could influence voting behaviour. For them, this was the point. (Ross, 2004:799, emphasis in original)

The majority of talk shows do not, however, feature senior politicians - their contribution instead re-inflected to the participating citizens by the journalist or chair. Participants in public access programming - phone-ins or studio audiences - are also inherently self-selective. That is, they typically hold an above average interest in politics and are motivated to articulate their citizenship in ways beyond simply casting a vote (see McNair et al., 2002), which echoes the perception of the public in other forms of mediated participation - such as letters to the editor (Wahl-Jorgensen, 2007). Evidently there is a broadcast tradition for public access programming that at least in principle seeks to empower ordinary citizens through expression of their opinions in a public space. When the BBC moved online it continued its public service commitment to civic engagement. The next section will discuss how this was articulated in policy terms and operationalised on the Corporation's election websites.

\section{ONLINE PARTICIPATORY SPACES}

Despite its late official arrival on the scene, the BBC quickly established itself as the leading British content site on the internet. The BBC website became known internally as the 'third broadcast medium' (Allan, 2006:37), and the BBC's commitment to the internet was very much based on extending its public service values as outlined above to the online domain. The 'historical' functions of the BBC more specifically also incorporates 'informing democracy and citizenship', to ensure people 'have the necessary knowledge to make informed decisions', and the Corporation acting 'as a technological pioneer' (Graf, 2004:68-69). Published in 2004 the Graf Report reaffirmed news and current affairs as a strategic priority for BBC Online, whilst retaining the inextricable link to citizens and democracy. Specifically the Graf report stated that BBC News Online:

should continue to provide fair, independent (national and local) news and current affairs coverage, ensuring citizens have the necessary knowledge to make informed choices and decisions and supporting the UK's democratic processes and institutions. The public value of this type of service will continue to grow, as more people use the internet as a - or even the - primary source of their news and basic information. (Graf, 2004:75)

The Neil Report, also published in 2004, reviewed the BBC's editorial processes and values in the aftermath of the Hutton Inquiry (see Barnett, 2005). This stated in relation to 'serving the public interest', for instance, that the $\mathrm{BBC}$ 'will provide a comprehensive forum for public debate at all levels' (Neil, 2004:7). Similarly, BBC's Producer Guidelines in 2005 further noted that 'news judgements at election time are made within a framework of democratic debate'. Moreover, in relation to new media services, the BBC Statements of Programme Policy for 2005/2006 devoted an entire section to explaining how 'our news and information service will be aimed primarily at creating democratic value and civic engagement' (BBC, 2005: 40). 
Online election news and information function in part to hold political power to account and empower citizens to make an informed decision about their electoral choice. Yet ordinary citizens are largely excluded from participation in such narratives, being cited only in exceptional circumstances and in response to elite sources (Thorsen, 2009). Instead, the BBC websites have since its inception contained experimentation with various forms of audience engagement, exemplified by different interactive features on the BBC micro websites for the 1997, 2001, 2005 and 2010 UK general elections. Justifying such interactive features in terms of public service, the Editor of BBC Interactivity, Vicky Taylor, argued that it is 'much better if you're getting your audience telling you what they think than just the officials or people in power [...] it's a form of democracy - more people get their chance to have their say about something' (Taylor, 2007, interview). Yet many of the features were not fully developed or were indicative of innovative forms of use at the time being held back either by technological limitations, by policy restrictions, or even by people's inexperience of engaging in online participatory spaces.

Online participatory spaces engendered by the BBC election websites can be broadly classified as: 1) opportunities for people to post questions that may be used by a journalist to question politicians, 2) forums facilitating debate among different members of the electorate, 3) ability for people to comment on BBC blogs or stories, 4) ability for people to post original stories on defined sections of the BBC website. It is possible to argue that Twitter and Facebook may represent a fifth type of online participatory space, though this falls outside the scope of this chapter since the Corporation was engaging there with audiences outside the confines of its own website. The way in which these opportunities for civic engagement were operationalized varied significantly from election to election. Crucially they also differed in the nature of dialogue they were designed to propagate.

The first type of participatory space, for instance, closely resembles the traditional broadcast model of public access programming wherein audience members are allowed a dialogue-by-proxy with elite sources via a correspondent or chair as an intermediary. Such mediated participation was given prominence and entitled Forum on both the 1997 and 2001 election websites. Whilst the Corporation continued the practice of asking audience members for questions to put to politicians, this was not highlighted as a distinct section or area of the 2005 and 2010 election websites. Online requests for questions to be put to politicians had instead been more closely integrated with existing BBC public access programmes. In other words, helping expand the reach of broadcast interaction rather than creating a distinct participatory space online.

The BBC's websites have been much more focussed around creating online spaces that harness public comments on a range of pre-defined issues and questions. These sections can essentially be seen as an attempt at facilitating debate between ordinary members of the electorate, without overt mediation by correspondents or engagement with politicians. In 1997 the BBC published a small selection of audience feedback in a section entitled You say!, followed up in 2001 with a similar feature entitled Talking Point. By the 2005 election audience discussions had been rebranded Have your say, which in turn became the moniker for the majority of the BBC's online discussions and was also a prominent feature during the 2010 election. These sections have 
increased in both prominence and volume of contributions. By way of example, during the 2005 election campaign there were 53 Have your say debates, which attracted 7,164 comments across all debates. However, the vast majority of contributions were never published due to a lack of resources and reliance on a manual copy/paste process (Thorsen, 2009). For the 2010 election campaign the Have your say section contained 83 debates, which in total attracted some 73,538 comments. By now the software and formal procedures for handling debates had evolved significantly, which ensured the vast majority of comments were published. The impact of this change on civic engagement and empowerment will be discussed in greater detail in the section below.

The third type of online participatory space relates primarily to the BBC's blogs, which went through a range of official and unofficial experiments before reaching its present form (Hermida, 2008, 2010). One of these early experiments was in fact BBC's 2005 election blog, entitled Election Monitor. By the end of the campaign, the blog had presented 276 posts (in addition to the main holding page), of which 189 received one or more comments from members of the public, totalling 783 comments across all blog posts. During the 2010 election, by comparison, there were 88 official BBC news blogs and no dedicated election blog. That is, rather than creating a dedicated blogging brand for the election, the Corporation's correspondent bloggers posted election updates on their existing blogs, using their personal identities as the brand. In other words, the shift here is one from product identity to individual journalists' identities. Of course, only a few of the 88 blogs had a specific focus on election issues. The main being political editor Nick Robinson's Newslog, business editor Robert Peston's Peston's Picks, and presenter of live political programmes, Andrew Neil's blog. There were also blogs related to flagship political programmes, including several each relating to Radio 4's Today programme, and television's Newsnight and the Politics Show.

The blogs serve a number of purposes - firstly allowing journalists to publish material that would not otherwise have made the news site (commenting on rumours or speculating on how events might develop); secondly to provide analytical commentaries with the blogger as the expert in the given field; thirdly to provide an increased degree of transparency and accountability of a publicly funded body ('The Editors' blog being one of the prime examples); and finally, to facilitate a direct dialogue between the BBC's audiences and its journalists, editors, and technical staff. The latter, however, remains somewhat of an ideal. That is, the blogs are acknowledged by many within the Corporation as effectively being a one-way communication from the BBC - despite attracting a great number of responses, these are often not responded to or even read by the original blog author. In other words, despite giving an impression of interaction, the blogs are often limited in their ability to facilitate a dialectical relationship between journalists and their audiences.

The final type of online participatory space encompasses features where audience comments are posted in response to an initial post by a member of the public (similar to a blog), or where audience comments are presented as a spectacle in and of itself. This is the most varied type of participatory space, but also the least developed on the BBC's election websites. For the 2001 election, the BBC commissioned ICM Research to conduct regular online surveys of a 2,000-strong voter panel, aimed to be representative of the UK adult population and not just Internet users. The feature was 
dubbed Online 1,000 (since only about half were expected to respond to the survey) and contained a new issue every month, and every week in the three weeks leading up to the election. Whilst it is a stretch to classify this as an online participatory space, it demonstrates the BBC's eagerness to harness a sense of public mood on given election issues.

For the 2005 election the Corporation adopted a more qualitative approach entitled The UK voters' panel. Created in collaboration with the BBC Breakfast television programme it was seemingly an evolution of the Online 1,000 feature from the 2001 election. However, this panel consisted of only 20 voters who had been asked in advance to contribute their views 'in text and in video, using $3 \mathrm{G}$ mobile phones,' throughout the election. There were nine different debate topics with an average of six panellists publishing a response on each occasion. People could discuss each of these entries and the section attracted some 524 comments. Whilst not a direct replacement, the only similar feature within the Election 2010 website was the new If I Were Prime Minister... video wall. This attracted 139 video clips through a combination of journalists actively seeking vox pops, and people submitting their own responses via the website. However, in stark contrast to the UK Voters' Panel, there was no opportunity to submit comments on the video entries and no text version of their contribution.

The public facing element of the online participatory spaces outlined above appear to fit well with the publically stated commitment to empower citizens at election time. By all accounts then the nature in which these public spaces are operationalized within the $\mathrm{BBC}$ is important to understand. This chapter will now turn to explore how the BBC's newsroom routines, editorial interpretations of policy, and technological challenges directly influences the ability of citizens to participate in these public spaces. The discussion will focus on the 2010 election website, comparing where relevant to the 2005 election website that differed significantly in how it was set up and managed.

\section{ROUTINES, AUTOMATION AND OUTSOURCING}

One of the most significant differences between the Election 2005 and Election 2010 micro-sites were the manner in which they were set up. The Election 2005 site was the consequence of a wide range of ad-hock decisions and uncoordinated input. Different teams from across the BBC were able to publish content, set up menu items and add new features without any centralised direction or steering. In contrast, the Election 2010 micro-site was treated as a project, delivered by a team responsible for strategy, development and co-ordination of content. The team included editors, journalists, programmers, designers and project managers from across the $\mathrm{BBC}$, including news, the user-generated content hub, and Future Media and Technology's journalism group.

The most overt change in relation to civic engagement from the Election 2005 to the Election 2010 site was the handling of comments submitted by citizens to the BBC website, particularly on the Have your say message boards. For the 2005 election temporary staff were hired to manage 'user-generated content' and were tasked with manually updating the Have your say message boards by copying individual comments from emails submitted via a web form into a webpage in the content 
management system. This process was resource intensive, preventing the vast majority of comments from being published and restricted the ability of contributors to engage each other's comments directly - thus stifling any sense of dialogue or deliberation among the citizens who had chosen to partake. During the interim years these message boards had undergone significant restructuring on several occasions, utilising two different systems. The first transformation was the introduction of a semi-automated system for moderating and publishing comments in October 2005. This was part of a commitment to publishing a much greater amount of comments than the previously resource intensive manual system, thus enhancing the sense of immediacy and ability for people to engage in meaningful dialogue. Several other features were also added at various stages, including comment recommendation and a debate status box indicating number of comments posted, rejected and awaiting moderation.

However, the system was unable to cope with the large demand from users. The Corporation therefore switched from the previous system to the one powering the BBC blogs on February 23, 2010. This allowed Have your say debates to take advantage of the Corporation's new authentication system, BBC iD, increased stability and scalability. Another important justification was to address the most common complaint from contributors to Have your say debates, that moderation of comments was still taking too long. 'We are not promising instant publication,' Editor of Interactivity, Alex Gubbay, announced at the time, 'but we are confident that moderation queues will be significantly reduced and the moderation process more transparent. With any luck, there should be a big improvement in your user experience' (Gubbay, 2010). Reflecting on the changes in an interview, Gubbay admitted that in the past 'on every debate, a significant percentage of comments that were submitted were not even looked at.' (Gubbay, 2010, interview). 'For the scale of the audiences we have', he argued, 'running what is in effect a message board becomes unsustainable' (Gubbay, 2010, interview). Aaron Scullion, Product Manager for the election website in BBC's Future Media \& Technology division, agreed that 'scale is always the problem for us at the BBC with comments'. Moreover, 'it's very hard to make the discussions generated by the communities in our user base useful to other people' (Scullion, 2010, interview). In so doing he drew attention to the importance of debates beyond those that are directly involved with commenting.

Although an improvement in certain areas as outlined above, the new system also lacked features that had been added by the previous restructuring - in particular the ability to recommend other comments. The ability for indirect or 'soft' participation and viewing of popular comments that had been possible was therefore lost only a couple of months prior to the election. Whilst admitting the current system was 'the first step in a gradual development of our interactivity' (Gubbay, 2010), there were no immediate plans to reintroduce the recommendation system, in part since it was deemed too prone to abuse by ideologues. Removal of the recommendation system was 'pure coincidence based on technical pragmatism', according to Scullion, and not 'deliberately removed just before the election so that people couldn't have their say about the government' as some had suggested. He concluded that the BBC's unique position as a public broadcaster meant 'no matter what we do in terms of recommendations, or curation, or automated selection of comments - somebody feels we have undermined their right to be heard' (Scullion, 2010, interview). 
The new system was limited in other ways too, with Assistant Editor for Interactivity and Social Media Development, Matthew Eltringham confessing to feeling 'personally, slightly frustrated by the software that we've got', since its 'structure doesn't do a great job of facilitating quality conversation'. Indeed the perceived 'quality' of Have your say debates has long been a source of contention within the Corporation. Most people interviewed for this project agreed Have your say was an effective way of facilitating 'civic engagement' and a worthwhile undertaking Eltringham, for example, argued: 'it's sharing information, it's articulation of policy issues, and it's engaging more broadly in the democratic process, rather than just the political process'. Some, however, dismissed the value of audience debates outright. The most extreme view was expressed, anonymously, by one senior BBC news executive who claimed the Corporation's online Have your say debates were 'shite' and 'a complete waste of time'.

Another major change compared to the 2005 election was that the moderation of comments submitted to the BBC's online debates had been outsourced to Capita, an external company that specialises in providing moderation services to commercial websites. Only comments that the company were unable to classify in accordance with the published guidelines and house rules would be passed on to the BBC for a decision on publication. Despite outsourcing this direct involvement in debates and therefore no longer being required to read all comments, the user-generated content team appeared much more conscious of the Corporation's role in actively partaking in debates. That is, to steer the audience discussion by posting new developments within the threads, or reminding people of the original topic. Eltringham defended this approach as 'an element of moderation, chairmanship and facilitation that you don't necessarily get in other forums'. In his view, despite outsourcing moderation, the $\mathrm{BBC}$ was 'providing a safer environment for people to comment'.

In the BBC's 2005 post-election evaluation the UK Voters' Panel was perceived to have required too many resources to develop and maintain, compared to the quality of output that was received from it. Reflecting on its discontinuation, Eltringham noted that 'it was hugely labour intensive, and I'm not sure that, in terms of quantity, we could really justify its continuation'. This effort, in his words, had not 'really matched the editorial gain'. Whilst not considering cost-effectiveness, this contradicts previous research that found the debates associated with these entries actually facilitated the most dialogic interaction between participants in the BBC's online debates (Thorsen, 2009). In other words, the online participatory space most effective as fostering a spectacle of civic engagement was discontinued due to editorial priorities, resource implications and internal perceptions about the quality it delivered.

For the 2010 election website, the new If I Were Prime Minister... video wall ended up being the BBC's showpiece of civic engagement online. However, there were conflicting views within the Corporation as to the exact nature of the feature ranging from viewing it as a great way to give citizens a voice during the election, to derogative views about quality of contributions and it being perceived to 'fill a gap on the page'. Contradictions were evident on several levels. The UGC team member responsible for managing the video wall, Helen Dafedjaiye, noted initially that 'its quite nice that we are getting certain people who know how to use technology, or are not afraid to use it, and send us in material unsolicited'. Yet when describing the process in detail, she professed: 
Normally they send us an email and we ring them up and ask if they can send us some video. And you have to ring them up like three times and say "have you got that video", "oh yes, I'm gonna do it", or "I've been having trouble". And then they will send it eventually. And it is sometimes a bit like pulling teeth. It takes a lot of effort just to get a little bit of video in. (Dafedjaiye, 2010, interview)

In addition to overcoming technical hurdles, there were also stylistic requirements that meant some submissions were rejected. One example was a post 'rejected because he talked about legalising weed, with his friend building up a splith in the background'. Others included children under 16 that provided their full name and where they lived, so could not be used for their own protection. Finally, Dafedjaiye noted that:

Other people didn't do it properly. They just said "I would do this", they didn't say "If I were a Prime Minister...", or they didn't say "my name is". So it was kind of like a standalone video clip. Didn't really work on their own. [...] They didn't follow the rules. (Dafedjaiye, 2010, interview)

Nevertheless, she noted that 'most people have been quite thoughtful about what they have said' and 'really passionate about what they would do'. Indeed the video wall was perceived within the UGC team as a significant success, in turn leading it to gain a permanent position on the BBC's 2010 election frontpage. This was contradicted by the BBC's Election 2010 Project Manager, Gareth Owens, who confessed he 'was never a fan of that' since in his view the 'quality of the stuff in it is pretty poor'. Far from being a spectacle of empowerment, he argued 'it was a desperate move to try to be more inclusive of our audience on this site' and that the section only gained a prominent position on the election frontpage since 'one of our other ideas was dying, for various technical reasons' (Owens, 2010, interview). In other words what could be perceived as the showcase of civic engagement and empowerment on the BBC's 2010 election website, was instead riddled with contradictions and gained prominence almost by accident.

\section{CONCLUSION}

Evidently there have been numerous attempts to facilitate online participatory spaces on the BBC election websites, being a natural extension of the Corporation's longstanding commitment to 'sustaining citizenship and civil society' (Department for Culture Media and Sports, 2005:5). These are subject to competing routines and editorial priorities that influence the nature of how civic engagement is engendered, which are not always immediately obvious through observing or participating in the debates. Outsourcing moderation has seemingly given up one intimate part of the 'chairmanship' espoused by Eltringham, for example. Moving from a manual to an automated system for publishing of comments might have increased participation levels, but the removal of recommendations has decreased ability for indirect participation. Moreover, whilst it is natural for an organisation the size of the BBC to have people with differing views on the 'quality' of audience debates, the conflicting interest across the Corporation appear at times to have left interpretation of civic engagement and empowerment of citizens to chance. There is also a natural tension in how the BBC seeks to make the participatory spectacle meaningful to passive 
observers by restricting to varying degrees how people can engage or articulate themselves - 'follow the rules' to empower others or be disempowered yourself. It is also stifling dialogue when the most interactive space from 2005, the UK Voters' Panel, is removed largely due to resource implications and replaced in 2010 with a one-way response to a predefined statement in If I Were Prime Minister...

As this chapter has demonstrated, the operationalization of the BBC's 'public space' is incredibly complex. The 'healthy democratic debate' envisaged by Mark Thompson as taking place in the BBC's 'public space' is a great ideal and reflects the Corporation's historical commitment to providing 'a forum for public debate' as discussed at the outset. But it is subject to existing and competing newsroom routines that have significant impact on how such public spaces foster civic engagement. Whilst there were attempts at cross-platform fertilization, the debates in participatory spaces engendered by the BBC election websites are more like isolated silos. Instead, the structural imperatives and routines of day-to-day newswork were in a way providing an illusory access or mediation of civic engagement - similar to the public access programming of television and radio. Indeed the tensions over perceived 'quality' of debate may also echo the early radio talk shows where audiences were initially unaccustomed to articulating their views in a new, public forum. Yet, I would argue, however flawed, this increased attention to citizens' voices and spectacle of democratic debate is nevertheless an important contribution to the fabric of democratic society and the potential empowerment of British citizens.

\section{REFERENCES}

Allan, S. (2006) Online News: Journalism and the Internet. Maidenhead, Open University Press.

Allan, S. \& Thorsen, E. (2010) 'Journalism and Public Service: The Case of BBC News Online' in G. Meikle \& G. Redden (eds.). News Online: Transformation and Continuity. Basingstoke, Palgrave Macmillan. pp. 20-37.

Barnett, S. (2005) 'Opportunity or threat? the BBC, investigative journalism and the Hutton Report' in Stuart Allan (ed.). Journalism: Critical Issues. Maidenhead and New York, Open University Press. pp. 328-341.

BBC (2005) BBC Statements of Programme Policy for 2005/2006.

Born, G. (2002) 'Reflexivity and Ambivalence: Culture, Creativity and Government in the BBC'. Journal for Cultural Research. 6 (1-2).

Bourdieu, P. (1998) Bourdieu: on television and journalism. London, Pluto Press.

Curran, J. \& Seaton, J. (2003) Power Without Responsibility. 6th edition. London and New York, Routledge.

Department for Culture Media and Sports (2005) Review of the BBC's Royal Charter: A strong BBC, independent of government. Department for Culture Media and Sports.

Graf, P. (2004) Report of the Independent Review of BBC Online.

Gubbay, A. (2010) Changes to Have Your Say. The BBC Editor's Blog. HTTP: http://www.bbc.co.uk/blogs/theeditors/2010/02/changes_to_have_your_say.html (accessed: 19 May 2011).

Hermida, A. (2008) The BBC goes blogging: Is 'Auntie' finally listening? Presented at the 9th International Symposium on Online Journalism, University of Texas: University of Texas School of Journalism. pp. 1-23. 
-- (2010) 'Let's Talk: How Blogging is Shaping the BBC's Relationship with the Public', in Sean Tunney \& Garrett Monaghan (eds.). Web Journalism: a new form of citizenship? Eastbourne, Sussex Academic Press, pp. 306-316.

Herrmann, S. (2010) BBC News online coverage of Election 2010. The BBC Editor's Blog. HTTP:

http://www.bbc.co.uk/blogs/theeditors/2010/04/bbc_news_online_coverage_of_e 1.html (accessed: 19 May 2011).

Hibberd, M. (2003) 'E - Participation, Broadcasting and Democracy in the UK'.

Convergence: The International Journal of Research into New Media

Technologies. 9 (1), pp. 47-65.

Livingstone, S.M. \& Lunt, P.K. (1994) Talk on television : audience participation and public debate. London; New York, Routledge.

MacDonnell, J. (1991) Public service broadcasting: a reader. London, Routledge.

McNair, B. (2000) Journalism and Democracy: An evaluation of the political public sphere. London and New York, Routledge.

McNair, B., Hibberd, M. \& Schlesinger, P. (2002) 'Public Access Broadcasting and Democratic Participation in the Age of Mediated Politics'. Journalism Studies. 3 (3), pp. 407-422.

Neil, R. (2004) The BBC's Journalism After Hutton: The Report Of The Neil Review Team.

Ross, K. (2004) 'Political talk radio and democratic participation: caller perspectives on Election Call'. Media Culture and Society. 26 (6), pp. 785-801.

Thompson, M. (2010) Planning the BBC's election coverage. The BBC Editor's Blog. HTTP: http://www.bbc.co.uk/blogs/aboutthebbc/2010/04/planning-the-bbcselection-cov.shtml (accessed: 19 May 2011).

Thorsen, E. (2009) News, Citizenship and the Internet: BBC News Online's Reporting of the 2005 UK General Election. Bournemouth, Bournemouth University.

-- (2010) 'BBC News Online: A Brief History of Past and Present' in N. Brügger (ed.). Web History. New York, Peter Lang, pp. 213-232.

-- (2011) 'The Second Digital Wave: BBC News Online, Embedded Video and the iPlayer', in Burns, M. and Brügger, N. (eds) Histories of Public Service Broadcasters on the Web, Peter Lang: New York, pp. 17-30.

Thorsen, E., Allan, S. \& Carter, C. (2009) 'Citizenship and Public Service: The Case of BBC News Online', in G. Monaghan \& S. Tunney (eds.). Web Journalism: A New Form of Citizenship? Eastbourne, Sussex Academic Press, pp. 116-125.

Wahl-Jorgensen, K. (2007) Journalists and the public: newsroom culture, letters to the editor and democracy. Cresskill, NJ, The Hampton Press. 